\title{
Spatial analysis of migrating Apis mellifera colonies in Salvador, Bahia, Brazil
}

\author{
Renato L. Jr. Sandes ${ }^{1}$, Cláudia L. Oliveira ${ }^{2}$, Edvana S. Ferreira ${ }^{3}$, Emersom Cruiff ${ }^{1}$, Cezar \\ Tavares $^{4}$, Antonio C.B. Santos ${ }^{1}$, Carlos R. Franke ${ }^{1}$, Maria E. Bavia ${ }^{1}$ \\ ${ }^{1}$ Department of Preventive Medicine, Federal University of Bahia, Salvador, Bahia, Brazil; ${ }^{2}$ National \\ Foundation of Health, Belo Horizonte, Minas Gerais, Brazil; ${ }^{3}$ Catholic University of Salvador, Salvador, \\ Bahia, Brazil; ${ }^{4}$ Statistician, Salvador, Bahia, Brazil
}

\begin{abstract}
Beekeeping in Brazil is growing but also associated with an increase in the number of human and animal accidents involved. In particular, bees of the Apis mellifera species (Africanized bees) are known for their aggressive behaviour and frequent swarming activity due to their poor adaptation to the human environment. This study analyzed the spatial distribution of occurrences of migratory swarms of A. mellifera and recorded apicultural accidents in the city of Salvador, Bahia, Brazil. The association of demographic and climatic variations on places where the swarms occurred was also evaluated. The study is based on data collected within the frame of the "SOS Bees", a project initiated for the protection of the environment and enforced by a special unit of the military police in Bahia. In the 3-year period from 2000 to 2003, 590 swarms were registered in 75 of the 98 zones of information of Salvador. Three cluster areas, representing $25.4 \%$ of all events, were identified. In that period, 316 apicultural accidents were registered involving humans and one involving dogs. The seasonal rise of the monthly average temperature showed an association with the increase of the number of swarming events.
\end{abstract}

Keywords: Africanized bees, Apis mellifera, migrating bees, swarming, geographical information system.

\section{Introduction}

The species Apis mellifera, introduced into Brazil in 1839 , used to be the only representative of the family Apidae in the country. Each hive is an extraordinarily organized colony of about 80,000 bees, the great majority of which are laborers which constitute the workforce of the hive. The remaining bees consist of the solitary queen and about 400 drones (Silva, 1985; Pereira et al., 2003).

Most of the Brazilian bee population came originally from Europe. However, in mid-1956, a group of

Corresponding author:

Renato L. Jr. Sandes

Department of Preventive Medicine

Federal University of Bahia

Salvador, Bahia, Brazil

Tel./Fax +55 7191339889

E-mail: sandesrjr@yahoo.com.br
African bee queens (A. mellifera scutellata), taken to Brazil with the intention to improve honey production, accidently escaped resulting in an uncontrolled "Africanization" of existing populations. As a result, the pure European A. mellifera bees were rapidly being replaced by Africanized ones (Soares, 1998; Santos, 2002). To counter this development, a specialized unit of the military police of Bahia, i.e. the Police for the Protection of the Environment (PPE), pioneered a service in 1986 that entailed the capture and relocation of bee swarms lodged in inappropriate places. This was done as part of the project "SOS Bees" that was not only initiated to minimize the risk for people and domestic animals, but also to prevent the destruction of these swarms.

Various approaches have been used to study this issue. However, distribution analyses of bee swarms in urban areas, particularly in large cities, are rare (Bailey and Gatrell, 1995). The present study is an 
attempt to analyze the spatial distribution of occurrences of migrating $A$. mellifera swarms in the city of Salvador, Bahia, Brazil, in the 4-year period of 2000-2004. The study is based on geo-processing techniques and takes into account the influence of climatic and demographic variables in the localization of these events.

\section{Materials and methods}

\section{Study area}

The study was carried within the city limits of Salvador, the capital of the State of Bahia, Brazil, located around $13^{\circ} 00^{\prime} \mathrm{S}$ and $38^{\circ} 30^{\prime} \mathrm{W}$ and at an average altitude of $50 \mathrm{~m}$ above sea level in the northeast region of Brazil. With 2,673,560 inhabitants, Salvador is the third most populous city in the country (IBGE, 2000). Salvador has a surface area of $707 \mathrm{~km}^{2}$ and a population density of 3,840 inhabitants per $\mathrm{km}^{2}$ (IBGE, 2000). The climate is predominantly hot and tropical with rains both in winter and summer. The maximum monthly average temperature during the study period was of $27.7^{\circ} \mathrm{C}$ (January, 2003) and the minimum was $23.5^{\circ} \mathrm{C}$ (August, 2000) (INMET, 2005).

Capture and relocation of the migrating A. mellifera swarms

The localization and rescue of the swarms was carried out by the PPE, which was generally notified when an inappropriately installed beehive was found. The motivation was the danger for nearby people and also to protect domestic animals. In practice, a team of specialized military policemen was dispatched to the address given with an order to remove the beehive in question and relocate it to an institution specialized in apiculture where it would be further handled by specially trained staff. This service is part of the project "SOS Bees", endorsed in the constitution of the State of the Bahia (1989), article 215, proposition IX.

Data on capture and relocation of swarms by the
PPE, carried out from January, 2000 to January, 2004, were collected and complemented by demographic data (IBGE, 2000), climatic data (INMET, 2005) and additional information such as the name and address of the solicitant, the month and year of occurrence and whether there was any accident(s) due to the presence and handling of the bees.

\section{Geographical information system construction}

All the addresses where migrating swarms had been retrieved were geo-referenced using a Magellan global positioning system (GPS) device (GPS Tracker- 12 canals).

The study was based on the grid of public parks, which is part of the cartographic base produced for the Urban Development Company of the State of Bahia (Conder, 2003), and the a grid based on 98 so-called zones of information (ZI) of Salvador (Fig. 1 ). The cartographic information was digitalized in the 1:2,000 scale of the Universal Transverse Mercator (UTM) projection (Conder, 2000).

\section{Statistical analyses}

Descriptive statistics were performed using SPSS version 13.0. The association between climatic variables (precipitation, humidity and temperature) and the monthly number of cases migrating bee swarms was done using the Pearson correlation coefficient at the $5 \%$ level of significance.

The spatial distribution of migrating swarms was studied using the SaTScan and CrimeStat ${ }^{\circledR}$ softwares. First, we checked for randomness of the point distribution by Ripley's K statistics (Ripley, 1977); second, we described the risk surface by kernel density estimation (Bithell, 1990; Kelsall and Diggle, 1995).

\section{Results}

During the study period (January, 2000 through January, 2004), 590 occurrences of A. mellifera swarms were registered in Salvador. The 2004 data $(n .=29)$ were excluded as the data for this year 


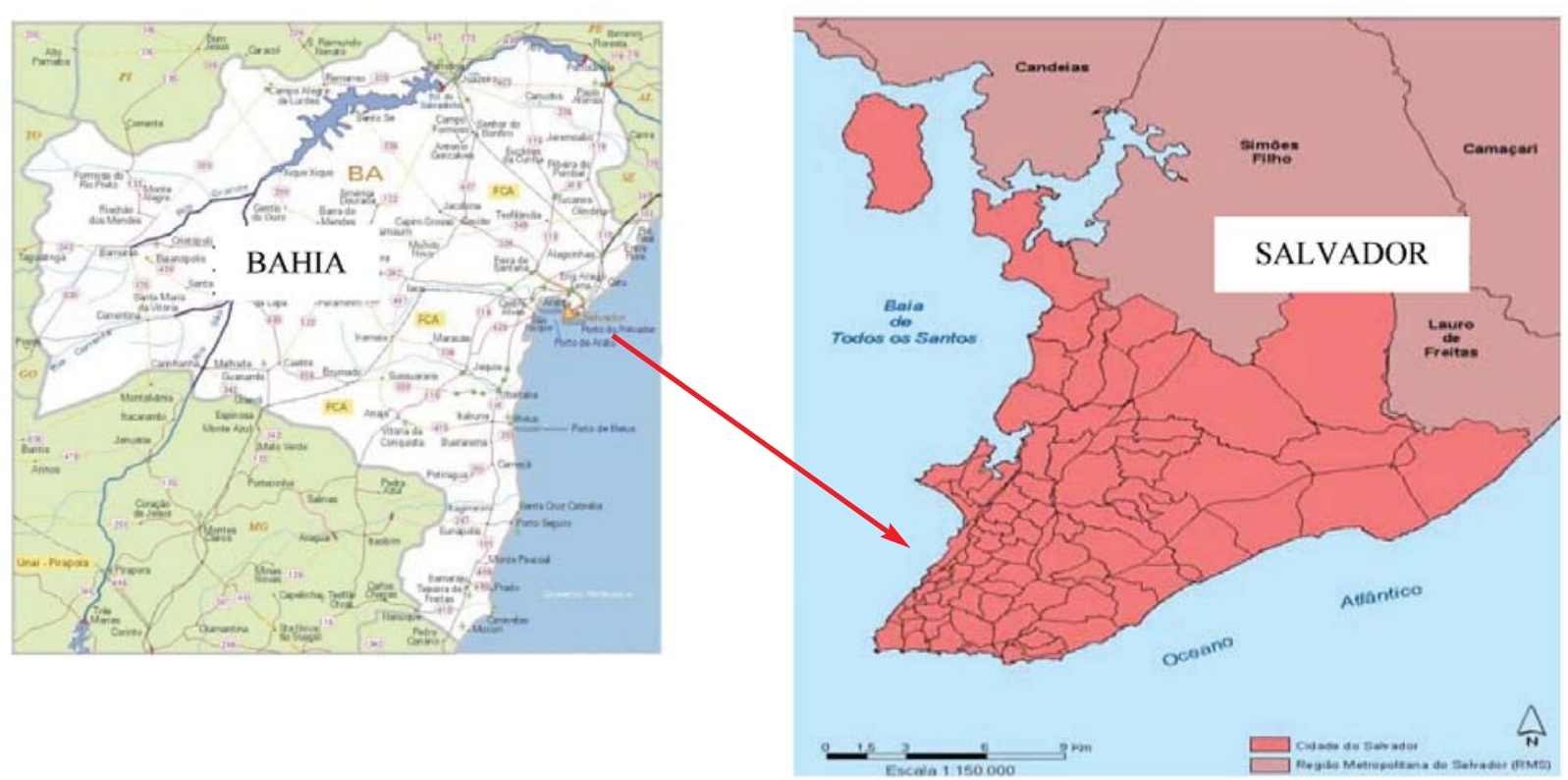

Fig. 1. Maps of the state of Bahia and the city of Salvador depicting the layout of the zones of information (ZI). Source: Conder, 2000.

were incomplete. A total of 561 events occurred between 2000 and 2003, hence an annual average of 140.3. In 2003, the recorded number was 4.1 times greater than the average of the period from 2000 to 2002 and represented $57.6 \%$ of the total of events considered in this study.

The analysis of the climatic variables revealed that the monthly averages of temperature correlated positively with the number of migrating swarms events $(\mathrm{P}<0.05)$. No correlation with humidity and precipitation was found.

During the study period (2000-2003), 316 accidents related to attacks by Africanized bees were registered. They consisted of 314 notifications in humans: $59.2 \%(186 / 314)$ in men and $40.8 \%$ $(128 / 314)$ in women. In addition, there was one human case where the sex of the person was not registered and there was one attack of a dog (Fig. 2).

The highest number of swarm notifications were found in a minority of ZIs, i.e. Piatã/Itapuã with 91 notifications, Pituba/Júlio Cesar Park with 30 notifications, Boca do Rio with 29 notifications, and 4 additional ZIs with 5 occurrences. Thus, 155 out of all
561 events $(27.6 \%)$ had taken place in only seven ZIs.

Two cluster areas were identified. The first one is ZI 55 (Piatã/Itapuã), with about 90,000 inhabitants, which was characterized as the primary cluster with

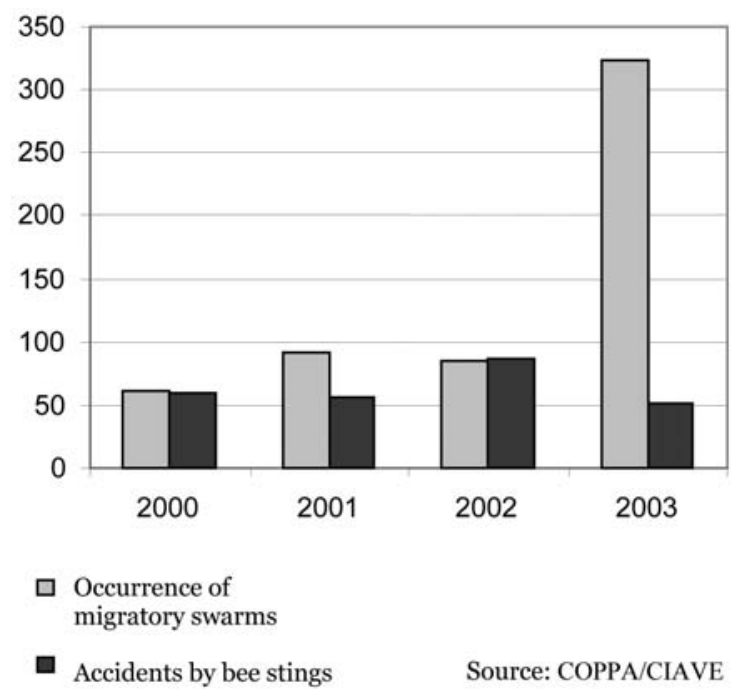

Fig. 2. Number of occurrences of migratory swarms and number of bee stings registered in Salvador, Bahia, in the period 2000-2003. 
91 occurrences. The estimated relative risk of occurrence of new swarms in this ZI is 4.8 times greater than that in the other areas. The second cluster area, with 103 events, is formed by a conglomerate of six ZIs and represents a population of 209,000 inhabitants. This area was considered to be the secondary cluster, and it corresponds to a greater relative risk, i.e. 2.3 times of new swarming.

The descriptive spatial analysis revealed that the swarming events in Salvador during the study period make up an average central area. A similarity was observed also between the central averages of the occurrences from 2000 to 2002 with inclusion of the respective ellipses. Although the central averages of the years 2001 and 2003 present similar positions on the map, the inclusion of the ellipse formed by the 2003 events approaches that of the years 2000 and 2002, whereas the area enclosed for the relative ellipse to the year of 2001 reproduces a shunting line of the set of the data towards the east (Fig. 3).

Figure 4 shows the estimates of the unvaried Ripley $\mathrm{K}$ function for migrating swarming in Salvador in the period from 2000 to 2003. The analysis may suggest evidence of existing aggregations of swarm migration due to proximity. The red lines (Lt) are mainly above the green (Ltmin) and blue (Ltmax) lines, suggesting that at longer distances bee swarming occurs randomly.

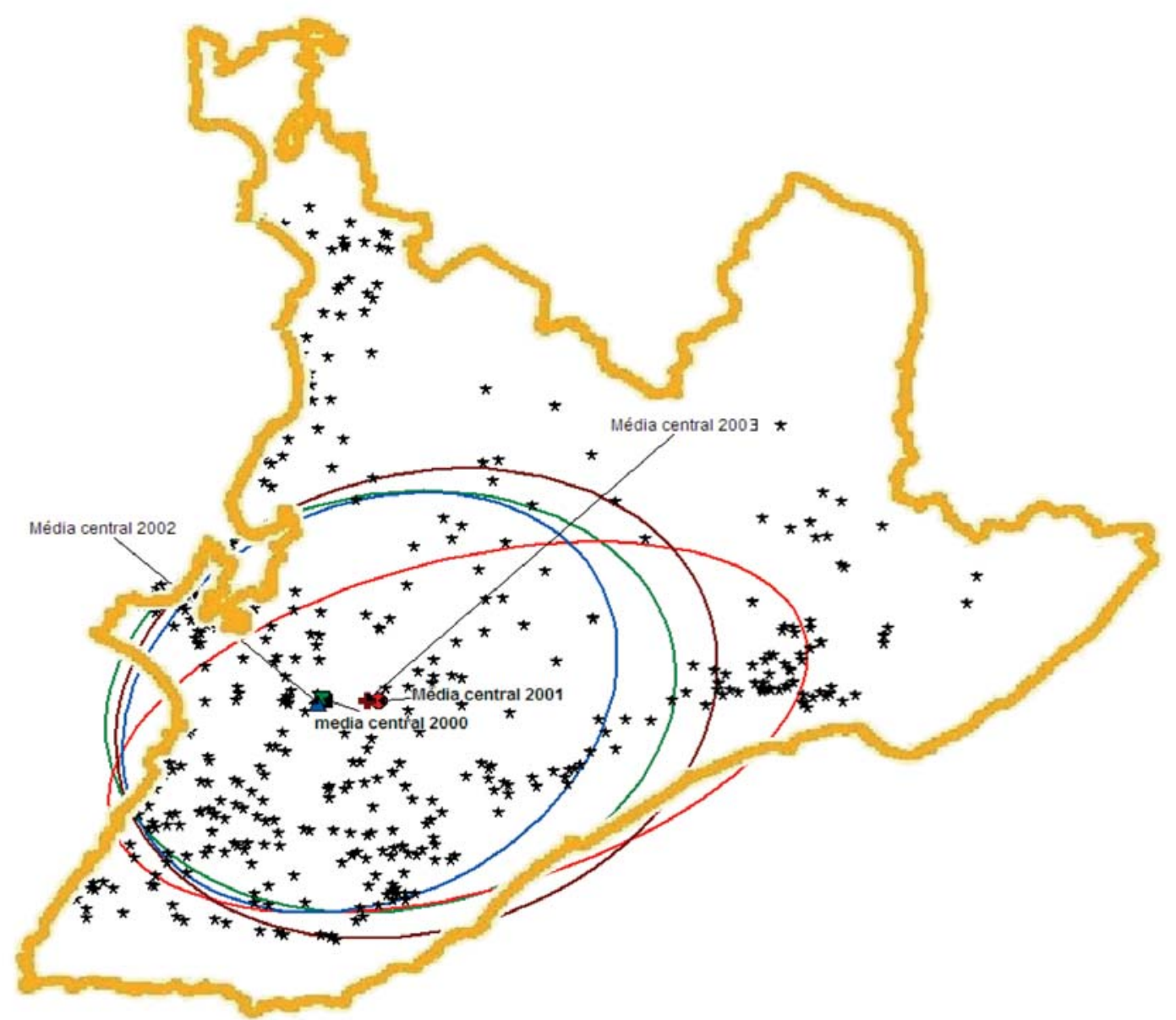

Fig. 3. Descriptive spatial analysis of the occurrences of migratory swarms in Salvador, Bahia, in the period 2000-2003, representing the central averages and the ellipses of shunting line standards for each year. 

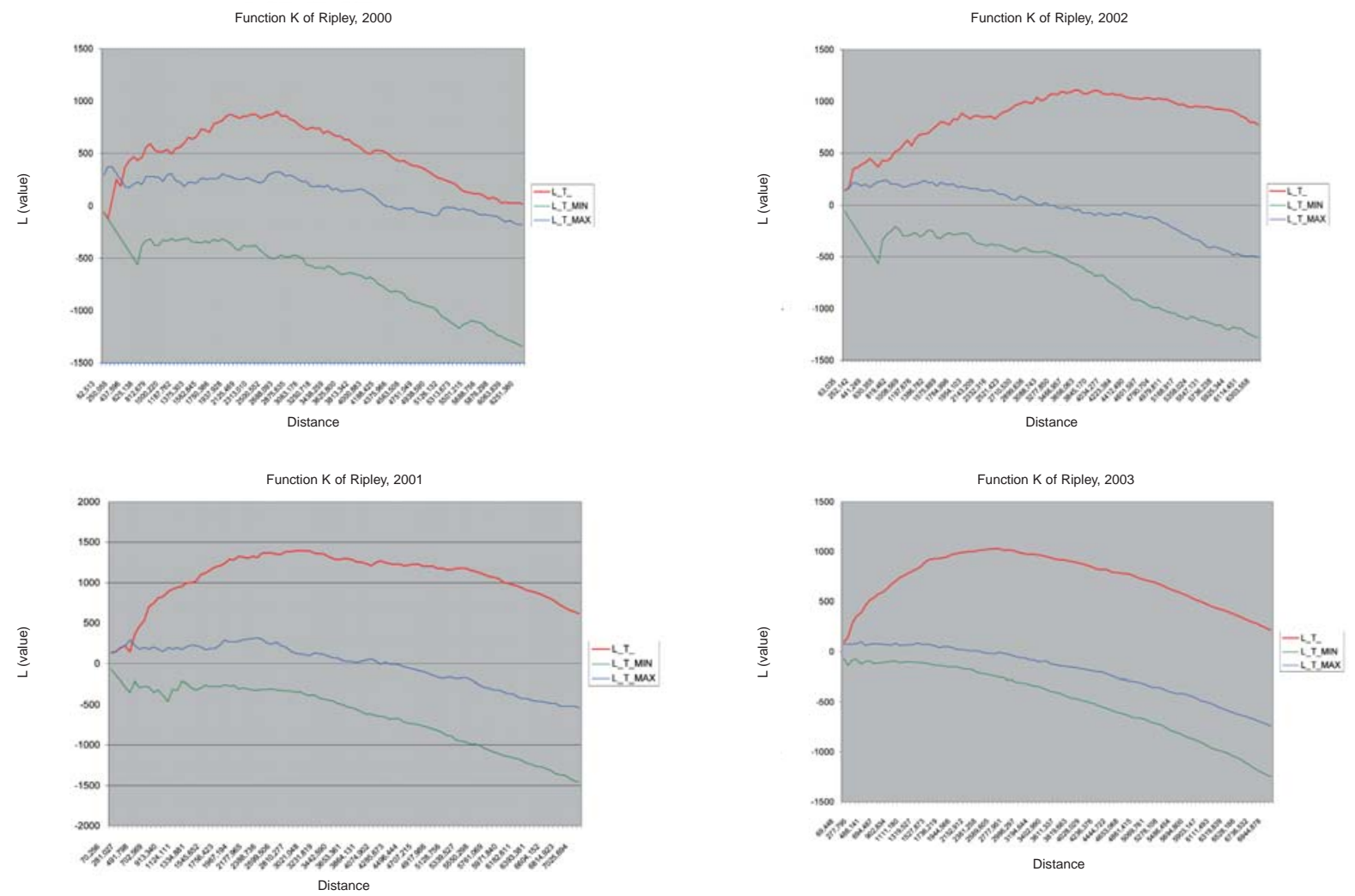

Fig. 4. Unvaried analysis of function $\mathrm{K}$ of Ripley of the standard of aggregation of the occurrences of migratory swarms of A. mellifera in the years of 2000 the 2003 in Salvador, Bahia, Brazil.

\section{Discussion}

The increase in the detection of bee swarming events in the city of Salvador, Brazil, registered by the service "SOS Bees" in 2003, is a consequence of the strategy adopted to prioritize this service, placing adequate amounts of materials and human resources to meet the real demand of Salvador's metropolitan population.

The month of March stood out every year during the study period because of the relative increase in the number of swarming events observed at this time. This corresponds probably to the peak of migration called "peak of abandonment" (March to May) described by Soares et al. (1998). The other annual increase, designated by Soares et al. (1998) as the "swarming peak" (August to October), which is due to increased access to food, was not observed in the interior of the state of Bahia. An explanation could be that this region of Salvador is not characterized by any particular "scarcity" season.

The analysis of the climatic variables revealed that the monthly averages of temperature correlated positively with the number of migrating swarm events $(P<0.05)$. No correlation was found with humidity and precipitation in Salvador in the study period.

In a previous study performed in the city of São Paulo, Mello et al. (2003) found a positive correlation between the number of notifications of $A$. mellifera (Africanized) colonies and the average daily temperature in the period of 1994 the 1997. The same authors also found a negative correlation between the number of bees and the relative air humidity. 
The results of the Kernel intensity analysis facilitated a general vision of the spatial distribution of the occurrences of migratory swarms in the city of Salvador in the period of 2000 to 2003. It was noticed that the colonization of migratory swarms reflects a high degree of adaptability of these insects. It was also observed that the number of occurrences of migratory swarms had increased in the quarters of Pituba and Itapuã and that these quarters had also undergone a considerable real estate expansion, corresponding to $30.8 \%$ and $22.7 \%$ in 1994 and 2000, respectively (SEPLAN, 2000). This fact suggests the existence of a cause and effect relationship between recent urban expansion and an increase in the frequency of notifications regarding the presence of migratory swarms in these areas. Factors such as the reduction of natural areas that could better shelter the swarms and/or the availability of attractive food sources for these insects are aspects that would have to be more thoroughly investigated to complement this pilot study.

The findings of the present investigation show that there is a real demand in Salvador for the services of capture and relocation of migratory swarms provided by the "SOS Bees". The increased number of treatments (n. $=590$ ) carried through in the period of January of 2000 to January of 2004 are evidence for utility of this intervention. The demand for the service of capture and relocation of swarms registered in the years of 2000, 2001 and 2002 clearly is minor when compared to 2003, the year of the greater investment in "SOS Bees" project. This needed adjustment of the human resources and material to the effective attendance of a higher number of requests, showing that the metropolitan area in the previous years was not given a priority. Finally, it was demonstrated that GIS is a tool well adapted for the evaluation of the spatial distribution and clusters formation with regard to migratory bee swarms.

\section{References}

Bailey T, Gatrell A, 1995. Interactive Spatial Data Analysis. Longman Scientific and Technical, London, UK.

Bithell JF, 1990. An application of density estimation to geographical epidemiology. Stat Med 9, 691-701.

Conder, 2000. Companhia de Desenvolvimento Urbano do estado da Bahia/Malha de Zonas de Informação.

Conder, 2003. Companhia de Desenvolvimento Urbano do estado da Bahia/Malha de Eixo de Logradouro.

IBGE, 2000. Instituto Brasileiro de Geografia e Estatística. Censo Demográfico.

INMET, 2005. Instituto Nacional de Meteorologia. http:// www. Inmet.gov.

Kelsall JE, Diggle PJ, 1995. Non-parametric estimation of spatial variation in relative risk. Stat Med 14, 2335-2342.

Mello MHSH, Silva EA, Natal D, 2003. Abelhas africanizadas em área metropolitana no Brasil: abrigos e influências climáticas. Rev Saú Púb 37, 237-241.

Pereira FDM, Lopes MTDR, Camargo RCRD, Vilela SLO, 2003. Produção de mel. Embrapa Meio-Norte - Sistema de Produção, Volume 3.

Ripley BD, 1977. Modelling spatial patterns. J Roy Stat Soc 39, 172-212.

Santos IA, 2002. A vida de uma abelha solitária. Ciência Hoje, 179 pp.

SEPLAN (Secretary of Planning of the city of Salvador), 2000. SALVADOR - COPLAN. Habitação em Salvador. Salvador, paginação irreg. il. color. graf, tab. mapas e fotos. (Coletânea de Estudos - PDDU).

Silva RMB, 1985. Curso de Apicultura. Nova Odessa, SP, Instituto de Zootecnia, 115 pp.

Soares AEE, 1998. Manejo de caixas iscas e suas implicações com a prevenção de acidentes. Congresso Brasileiro de Apicultura 12, 61-65. 